\title{
The effect of a knowledge-based ergonomic intervention amongst administrators at Aga Khan University Hospital, Nairobi
}

\author{
Nancy Wanyonyi ${ }^{\mathrm{a}, \mathrm{e}, *}$, Jose Frantz $^{\mathrm{b}}$ and Hassan Saidi ${ }^{\mathrm{c}, \mathrm{d}}$ \\ ${ }^{a}$ Department of Orthopaedics and Rehabilitation, School of Medicine, Moi University, Eldoret, Kenya \\ ${ }^{\mathrm{b}}$ Faculty of Community and Health Sciences, University of the Western Cape, South Africa \\ ${ }^{\mathrm{c}}$ Department of Human Anatomy, University of Nairobi, Kenya \\ ${ }^{\mathrm{d}}$ Kenyatta National \& Aga Khan University Hospital, Nairobi, Kenya \\ ${ }^{\mathrm{e}}$ Physiotherapy Department, University of the Western Cape, South Africa
}

Received 4 November 2013

Accepted 23 July 2014

\begin{abstract}
.
BACKGROUND: Low back pain (LBP) and neck pain are part of the common work-related musculoskeletal disorders with a large impact on the affected person. Despite having a multifactorial aetiology, ergonomic factors play a major role thus necessitating workers' education.

OBJECTIVE: To determine the prevalence of ergonomic-related LBP and neck pain, and describe the effect of a knowledge-based ergonomic intervention amongst administrators in Aga Khan University Hospital, Nairobi.

METHODS: This study applied a mixed method design utilizing a survey and two focus group discussions (FGD). A selfadministered questionnaire was distributed to 208 participants through systematic sampling. A one hour knowledge-based ergonomic session founded on the survey results was thereafter administered to interested participants, followed by two FGDs a month later with purposive selection of eight participants to explore their experience of the ergonomic intervention. Quantitative data was captured and analyzed using SPSS by means of descriptive and inferential statistics, whereas thematic content analysis was used for qualitative data.

RESULTS: Most participants were knowledgeable about ergonomic-related LBP and neck pain with a twelve month prevalence of $75.5 \%$ and $67.8 \%$ respectively.

CONCLUSION: Continual ergonomic education is necessary for adherence to health-related behaviours that will prevent work-related LBP and neck pain.
\end{abstract}

Keywords: Low back pain, neck pain, work-related musculoskeletal disorders (WRMDs), posture, exercises

\section{Introduction}

Low back pain is a leading musculoskeletal disorder with a lifetime prevalence of $60-85 \%[1,2]$, a one year prevalence of $0.8 \%-82.5 \%$, and a point prevalence

*Address for correspondence: Ms. Nancy E.N. Wanyonyi, Department of Orthopaedics and Rehabilitation, School of Medicine, Moi University, P. O. Box 4606-30100, Eldoret, Kenya. Tel.: +254 721 541080; E-mail: eileenwanyonyi@gmail.com. of $1 \%-58.1 \%$ [3]. Neck pain closely follows low back pain (LBP), with a prevalence of over 70\% [4], and is a major cause of activity limitation among workers [5-7]. These disorders have a multifactorial aetiology including physical, environmental and individual factors and their treatment associated with huge financial implications if not curbed early [8-10]. A study in the UK shows that a total of 303 employees (87\% self-referrals and $13 \%$ referred by their managers) reported to the 
occupational health physiotherapy center within one year out of which 862 booked physiotherapy sessions were attended and 320 cancelled [8]. An estimated average of 37,401 claims for work-related musculoskeletal disorders (WRMDs) per year was made in Washington with an average direct cost of USD 12, 377 per claim [11]. In a study conducted among New Zealand workers $(n=3003)$, the prevalence of reduced activities and absenteeism due to LBP was recorded at $18 \%$ and 9\% respectively [12].

Hospital administrators are exposed to prolonged sitting and long working hours, which in combination with the use of computers, predisposes them to ergonomic hazards and subsequently the development of most work-related neck pain and LBP [4, 13-17]. Regrettably, accurate data on the global prevalence of work-related musculoskeletal disorders (WRMDs) are difficult to obtain and compare across countries because of the lack of reporting of new cases as well as the multifactorial aetiology of WRMDs, including non-occupational factors $[18,19]$. A report on global work-related diseases estimated the prevalence of such disorders at 160 million per year [20]. In developed countries, WRMDs are the most common occupational health problems, accounting for over $50 \%$ of all occupational diseases with peaks of $85 \%$ and $80 \%$ in Spain and France respectively [21]. Statistics in Great Britain from a comparative study conducted between 2001 and 2011 shows a decreased trend in WRMDs prevalence to $1,700,000$ the year $2010 / 11$ from $2,200,000$ in the year 2001/02, while the total number of new cases of WRMDs reported in 2010/11 was 158,000 , down from 190,000 in the year 2009/10 [22].

Statistics on WRMDs within developing countries are scarce. Naidoo et al. [10] state that most documented work activities in the developing countries relate to agricultural work; however, the prevalence of any WRMDs in these countries range from $37 \%$ among a general population of workers to $92 \%$ among nurses. In addition, Rosenstock et al. [23] adds that globalisation has brought work-related hazards that developing countries lack the infrastructure and professional capacity to handle adequately. In Kenya, a developing country, the Ministry of Labour in 2004 estimated the number of occupational fatalities and injuries as 1387 [24]. This represented an estimated $0.0043 \%$ of the country's population $(32,021,856)$ in that year 2004 [25]. However, the Ministry of Labour in Kenya observed that, "more than half" of these occupational injuries would go unreported and this is partly because the majority of Kenya's workforce is in the informal sector, as well as the lack of provision of the necessary infrastructure by the Occupational Health and Safety (OHS), in terms of understaffing and finance [24, 26]. Since the 2004 statistical report on occupational injuries, no other similar report has been found issued by the Ministry of Labour or the Occupational Health and Safety, indicating a possible lack of reporting.

WRMDs can be avoidable and it is with this regard that more research needs to be carried out in developing countries to establish preventive measures regarding the neglected ergonomics-related hazards [27-30]. Increased knowledge in ergonomics as well as adherence to proper ergonomic requirements including work rest breaks have been shown to help decrease the draining effects of work-related LBP and neck pain thus helping decrease the disease burden of musculoskeletal disorders [31-36]. This study sought to determine the level of ergonomic knowledge of workers, the prevalence of WRMDs, the effect of a knowledge-based ergonomic intervention and the concepts that participants valued.

\section{Materials and methods}

\subsection{Research design}

A mixed methods approach was used in this study. The specific design was a partial mixed sequential dominant status, whereby the quantitative part assumed the dominant status [37].

\subsection{Population}

The study constituted of 458 hospital administrative staff that were defined in the study as any staff with office related jobs majorly constituting computerrelated tasks.

\subsection{Sampling}

Systematic sampling was done after using the Yamane's formula $\left(n=\frac{N}{1+N(\epsilon) 2}\right)$ to be able to calculate a sample that will allow generalisability of our study findings [38]. A minimum sample of 214 administrators was thus required.

\subsection{Materials}

A questionnaire that was divided into four parts was used for data collection in this study. Section one requested demographic characteristics of the 
participants, section two sought to determine the participants' biomechanical knowledge of LBP and neck pain occurrence as well as prevention behaviours, section three (a) consisted of the Nordic Musculoskeletal Questionnaire which is a standardised questionnaire used to analyse musculoskeletal disorders in an occupational environment [39], section three (b) involved follow up questions about the nature of LBP and neck pain, whereas section four enquired about the workrelated and individual risk factors to LBP and neck pain. These questions were from different standardised questionnaires as there was no single questionnaire that met all the objectives of this study [40, 41 (unpublished data), 42, 43].

The Nordic Musculoskeletal Questionnaire was validated regarding content, wording and response construction and tested for reliability. A kappa value of between 0.48 and 0.72 was reached, which demonstrated the reliability of the instrument being studied [39]. A pilot study of the survey questionnaire was done and it revealed test-retest reliability, especially for the unstandardized questions. The researcher calculated the internal consistency of the remaining part of the questionnaire, using data from the test-retest of the questionnaire among the same participants. A Cronbach's alpha value of 0.881 was established, indicating good internal consistency reliability. There was a strong correlation between answers from the first round and the second round, with ranges of $0.71-1.00$ Pearson's correlation coefficient for continuous variables, and there was no significant change $(p<0.05)$ for categorical variables using Mcnemar's test. Content validity of the questionnaire was assessed through peer reviewing, as well as by experts in the field to assess the adequacy of coverage of the content area being measured. The content validity used in this study was therefore a completely qualitative approach whereby the experts verified the content as being valid without quantifying it. Experts in the field also assessed the content validity of the intervention that was carried out as part of the survey. A knowledge-based ergonomic intervention founded on the results of the survey was administered to interested participants two weeks after collection of the questionnaires. A month thereafter, two focus group discussions were held by use of an interview guide and purposive selection of eight participants.

\subsection{Data collection methods}

Data was collected by means of a survey and focus group discussions (FGD). The flow chart in Fig. 1 further illustrates the data collection procedure. The survey was done by distributing 278 questionnaires to determine the prevalence of WRMDs, the biomechanical knowledge of LBP and neck pain occurrence as well as prevention behaviours. Two weeks later, a total of

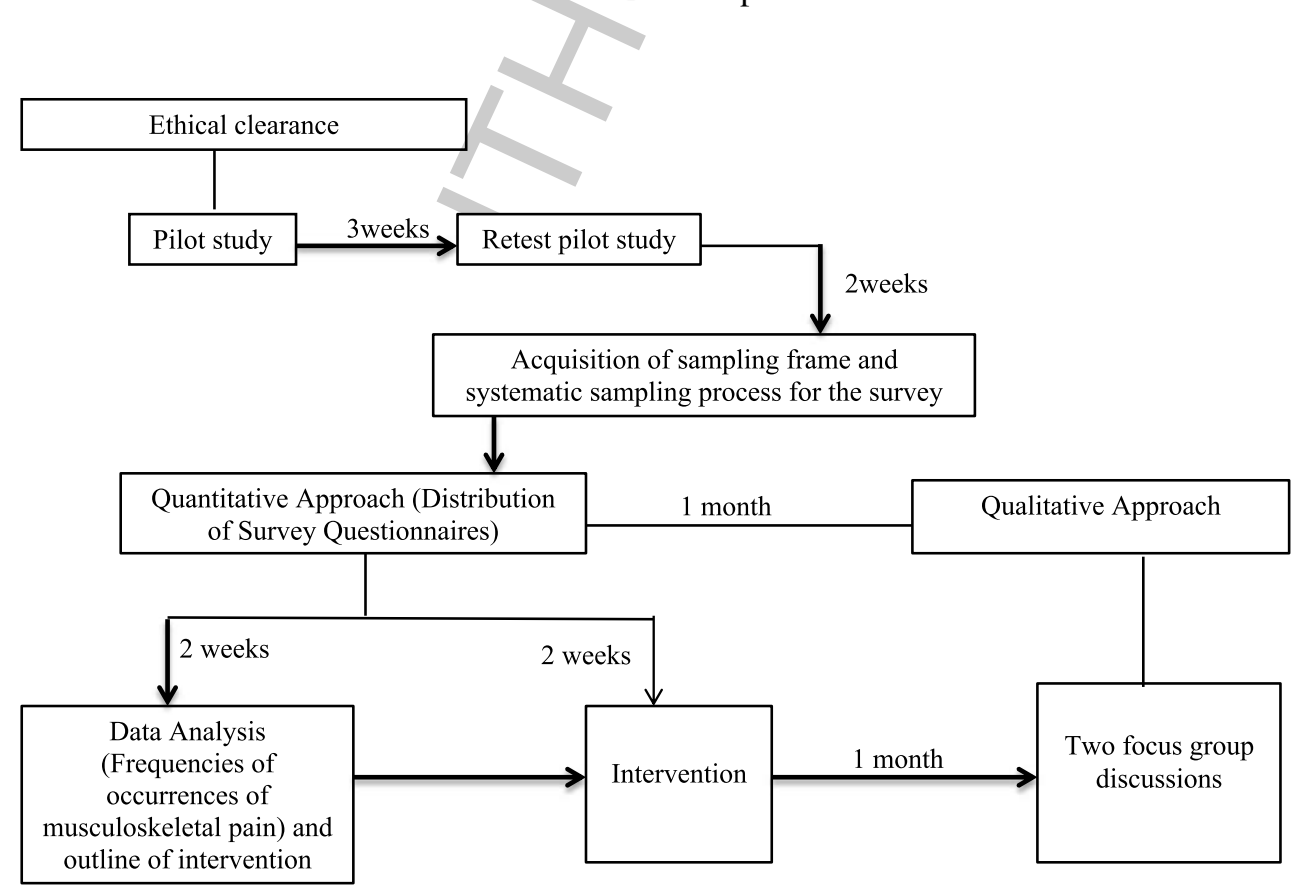

Fig. 1. Flow Chart of data collection procedure. 
200 questionnaires which represented $93.5 \%$ of the minimum expected feedback $(n=214)$ were received. The questionnaires received as of that time allowed descriptive analysis of the frequency of occurrences of musculoskeletal disorders by SPSS version 22 as the researcher did a follow-up of the remaining questionnaires. Low back pain and neck pain were the most prevalent musculoskeletal disorders among the staff, followed by the shoulder, upper back, ankles and wrist respectively. These findings enabled the researcher to design a knowledge-based ergonomic intervention to address these common disorders experienced by the administrators.

The intervention incorporated PowerPoint educative slides targeting the adjustment of work posture and preventative practices at work, including rest breaks and stretch exercises [15, 36, 44-49]. This educative slideshow was supplemented by exercise pamphlets for home programme exercises as well as office exercises for the highly affected areas, i.e. low back, neck, shoulders, upper back, ankles and wrists respectively [50-52]. Due to the complexities of gathering participants at a single point at one time, a total of eight sessions of the intervention were done at different venues to all the interested participants. One month after the intervention, the researcher purposively selected two participants from each of the eight interventions and grouped them equally in two focus groups, to be interviewed on different days. The invitation and information sheet regarding the focus group discussions were sent through electronic mail. A reminder mail was sent to the participants on the morning of the day scheduled for the FGD; however, only four participants showed up for both FGDs respectively. The purpose of the FGDs was to explore and describe the concepts that the participants valued from the knowledge-based ergonomic intervention. Questions guiding the focus group discussions were formulated with the guidance of literature around work-based ergonomic interventions. The interview guide asked the participants about the impact and lifestyle changes made after the intervention as well as the challenges faced and the possible recommendations towards the intervention. The FGD was moderated by the researcher and the two research assistants assisted in taking notes. Ethical clearance and approval was obtained from the University of the Western Cape Senate committee, National Council of Science and Technology as well as from the research institution $(\mathrm{AKUH}, \mathrm{N})$ for the study to be conducted. Informed consent was also obtained before the survey and FGD and referral was made where necessary.
Quantitative data was captured and analysed using the Statistical Package for Social Sciences (SPSS) version 20, and was presented in the form of descriptive statistics and the Chi-square statistic test for association with $p<0.05$ was used. The knowledge section consisted of thirty items, of which twenty-two items were knowledge questions, whereas the remaining eight were behavioural. This section used two formats of questions, i.e. the forced Likert scale of rating, ranging from 1 "strongly disagree" to 6 "strongly agree" as well as True, False and Not Sure answers. During analysis, the forced Likert scale was summed up to represent Agreed, Disagreed and Not Sure responses so as to fit in style with the True, False and Not Sure answers. The knowledge and behaviour questions were separated during the analysis process and the responses were then scored in relation to the three responses of Agreed, Not Sure and Disagreed. Each of the three responses had a score of 1 ; the highest score (3) meant a better self-reported knowledge; 2 meant moderate knowledge; whereas 1 represented poor knowledge. The same principle was applied to the behavioural practice section. Items expressed in a negative way, like "Weakness of the arm and hands cannot be caused by neck pain" had to be reversed during analysis so as to fit the actual rating pattern for the positive items. Thematic content analysis in terms of themes and categories was used for analyzing qualitative data. Several generic steps of making sense of the qualitative data inclusive of the four techniques of trustworthiness, i.e. credibility, transferability, confirmability and dependability, was continually done to warrant valid data [53]. The tape-recorded interview was played back to the participants so as to confirm and obtain clarity of what was discussed in the interviews, and thereafter transcribed verbatim to produce a transcript. Comparison was made with the field notes taken during interviews to verify accuracy and also reflexivity was used during data analysis to minimize the researcher's bias.

\section{Results}

A majority of the study participants were female $(58.5 \%)$ and the most frequently reported age group was $31-40$ years $(49.2 \%)$. Most of the study participants $(77.4 \%)$ worked while seated $80 \%$ of the time. The demographic characteristics are as presented in Table 1. Most study participants were knowledgeable about the occurrence of ergonomic-related LBP and neck pain and its prevention techniques (mean 
Table 1

Demographic characteristics

\begin{tabular}{lc}
\hline Variable & Frequencies $(\%)$ \\
\hline Gender $(n=207)$ & \\
Males & $86(41.5 \%)$ \\
Females & $121(58.5 \%)$ \\
Age group $(n=199)$ & \\
18-25 years & $19(9.5 \%)$ \\
$26-30$ years & $56(28.1 \%)$ \\
$31-40$ years & $98(49.2 \%)$ \\
$41-50$ years & $23(11.6 \%)$ \\
$51-60$ years & $3(1.5 \%)$ \\
Marital status $(n=205)$ & \\
Single & $77(37.6 \%)$ \\
Married & $118(57.6 \%)$ \\
Divorced & $1(0.5 \%)$ \\
Separated & $2(1.0 \%)$ \\
Other & $7(3.4 \%)$ \\
Educational Level $(n=206)$ & \\
High School & $7(3.4 \%)$ \\
A-Level & $1(0.5 \%)$ \\
College & $94(45.6 \%)$ \\
University & $83(40.3 \%)$ \\
Masters & $20(9.7 \%)$ \\
PHD & $1(0.5 \%)$ \\
Occupation $(n=208)^{\mathrm{a}}$ & \\
Sit $>80 \%$ of the day & $161(77.4 \%)$ \\
Sit $<80 \%$ of the day & $47(22.6 \%)$ \\
\hline$a$ - No missing values. &
\end{tabular}

$a$ - No missing values. knowledge score of 2.72 out of 3 ). The knowledge of the participants regarding various aspects relating to occurrence of ergonomic-related LBP and neck pain and the prevention techniques is reflected in Table 2.

Despite good knowledge, the participants did not have sufficient behavioural changes with this regard. With regards to behaviour (Table 3), a majority of the participants (46.3\%) and (49\%) respectively agreed that they sought help when lifting a heavy load as well as having exercise for at least ten minutes three times a week. Eighty-seven per cent agreed to walking short distances instead of using a car and $67.8 \%$ disagreed to carrying two bags together on one side. More than half of the participants $(64.7 \%)$ were not sure if they maintained an upright posture for the whole day as well as if they bent their backs fully when picking something from the floor $(43.8 \%)$. Majority of the study participants $(55.6 \%)$ reported twisting their backs while on their job and $43.4 \%$ expected the doctor/therapist to send them for an x-ray, MRI or Ct-Scan.

LBP $(75.5 \%)$ and neck pain $(67.8 \%)$ were the most prevalent musculoskeletal disorders in this setting, according to the Nordic musculoskeletal questionnaire (Table 4). Only LBP showed statistically significant associations $(p<0.05)$ with gender (Chi-square test for independence (with Yates Continuity Correction)

Table 2

Knowledge variables frequency table $(N=208)$

\begin{tabular}{|c|c|c|c|c|}
\hline Variables & $\begin{array}{l}\text { Disagreed } \\
n(\%)\end{array}$ & $\begin{array}{c}\text { Not sure } \\
n(\%)\end{array}$ & $\begin{array}{l}\text { Agreed } \\
n(\%)\end{array}$ & $\begin{array}{r}\text { Maximum } \\
\text { Score (3) }\end{array}$ \\
\hline Neck pain can cause pain to the shoulders and down the arm & $7(3.4)$ & $46(22.4)$ & $152(74.1)$ & 3 \\
\hline Physically active people get less back pain and recover faster if they do & $11(5.4)$ & $56(27.5)$ & $137(67.2)$ & 3 \\
\hline Poor posture is harmful to my spine & $12(5.9)$ & $8(3.9)$ & $183(90.1)$ & 3 \\
\hline Including neck exercises in treatment reduces pain and improves function & $5(2.4)$ & $67(32.7)$ & $133(64.9)$ & 3 \\
\hline Back pain settles quickly enough for one to get on with normal activities & $52(26.3)$ & $101(51)$ & $45(22.7)$ & 2 \\
\hline Smoking is not associated with neck pain & $46(22.5)$ & $83(40.7)$ & $75(36.8)$ & 2 \\
\hline A neck/cervical collar is indicated for all neck pain & $67(33.7)$ & $96(48.2)$ & $36(18.1)$ & 2 \\
\hline Psychological factors can contribute to the development of low back pain ${ }^{\mathbf{a}}$ & $24(11.5)$ & $66(31.7)$ & $118(56.7)$ & 3 \\
\hline Surgery is the most effective way to treat back trouble & $155(75.6)$ & $46(22.4)$ & $4(2.0)$ & 3 \\
\hline After back pain recovery patient is cured and there's no risk of further crises & $110(54.2)$ & $75(36.9)$ & $18(8.9)$ & 3 \\
\hline If you have backache you should avoid exercises. & $127(61.4)$ & $63(30.4)$ & $17(8.2)$ & 3 \\
\hline The spine is one of the strongest parts of the body & $28(13.7)$ & $36(17.6)$ & $140(68.6)$ & 3 \\
\hline Back pain is not usually due to any serious disease & $59(29.2)$ & $57(28.2)$ & $86(42.6)$ & 3 \\
\hline People with backache often have a slipped disc or entrapped nerve & $54(26.9)$ & $96(47.8)$ & $51(25.4)$ & 2 \\
\hline A bad back should be exercised & $23(11.4)$ & $53(26.2)$ & $126(62.4)$ & 3 \\
\hline Medication's the only way of relieving back trouble & $167(82.7)$ & $23(11.4)$ & $12(5.9)$ & 3 \\
\hline Strengthening and stretching exercises are very good for the neck & $9(4.5)$ & $21(10.4)$ & $172(85.1)$ & 3 \\
\hline Bed rest for $>1$ or 2 days is not a good idea if you have back ache* & $56(28.0)$ & $91(45.5)$ & $53(26.5)$ & 2 \\
\hline Weakness of the arm and hands cannot be caused by neck pain* & $66(32.0)$ & $107(51.9)$ & $33(16)$ & 2 \\
\hline $\begin{array}{l}\text { Work shifts, workload and support from supervisors } \\
\text { aren't contributing factors to neck pain* }\end{array}$ & $90(44.3)$ & $67(33.0)$ & $46(22.7)$ & 3 \\
\hline Abdominal exercises are not beneficial for my low back pain* & $93(45.4)$ & $92(44.9)$ & $20(9.8)$ & 3 \\
\hline Headaches can never be caused by neck pain* & $128(64.3)$ & $54(27.1)$ & $17(8.5)$ & 3 \\
\hline
\end{tabular}

* - The reversely asked questions whose disagreed response was stated to be correct, ${ }^{\mathbf{a}}$ - no missing values, (3) is the highest score per variable indicating good knowledge. 
Table 3

Behaviour practice frequency table $(N=208)$

\begin{tabular}{|c|c|c|c|c|}
\hline Variables & $\begin{array}{c}\text { Disagreed } \\
n(\%)\end{array}$ & $\begin{array}{c}\text { Not sure } \\
n(\%)\end{array}$ & $\begin{array}{c}\text { Agreed } \\
n(\%)\end{array}$ & $\begin{array}{r}\text { Maximum } \\
\text { Score (3) }\end{array}$ \\
\hline I maintain an upright posture for the whole day & $49(23.7)$ & $134(64.7)$ & $24(11.6)$ & 2 \\
\hline When I pick something on the floor I bend my back fully & $48(23.9)$ & $88(43.8)$ & $65(32.3)$ & 2 \\
\hline I seek help whenever I lift a heavy load & $30(14.8)$ & $79(38.9)$ & $94(46.3)$ & 3 \\
\hline I will exercise for at least 10 minutes at least three times a week ${ }^{\mathbf{a}}$ & $28(13.5)$ & $78(37.5)$ & $102(49)$ & 3 \\
\hline I'd expect my doctor/therapist to send me for an X-ray, MRI, C-T Scan & $31(15.1)$ & $85(41.5)$ & $89(43.4)$ & 1 \\
\hline I tend to twist my back while on my job & $42(20.5)$ & 49 (23.9) & $114(55.6)$ & 1 \\
\hline If I have two bags, I put them together and carry on one side & $139(67.8)$ & $18(8.8)$ & $48(23.4)$ & 3 \\
\hline I will walk short distances instead of using a car & $24(11.7)$ & $3(1.5)$ & $178(86.8)$ & 3 \\
\hline
\end{tabular}

a - no missing values, $(\mathbf{3})$ is the highest score per variable indicating good behavioural practice.

Table 4

Prevalence of musculoskeletal disorders $(N=208)$

\begin{tabular}{lcc}
\hline Body parts & $\begin{array}{c}12 \text { Month } \\
\text { prevalence N }(\%)\end{array}$ & $\begin{array}{c}1 \text { Week } \\
\text { prevalence N (\%) }\end{array}$ \\
\hline Neck & $141(67.8 \%)$ & $49(34.8 \%)$ \\
Shoulders & $119(57.2 \%)$ & $37(31.1 \%)$ \\
Upper back & $96(46.2 \%)$ & $40(41.7 \%)$ \\
Elbows & $37(17.8 \%)$ & $12(32.4 \%)$ \\
Wrist/hands & $72(34.6 \%)$ & $22(30.5 \%)$ \\
Lower back & $157(75.5 \%)$ & $74(47.1 \%)$ \\
Hips/thighs & $53(25.5 \%)$ & $15(28.3 \%)$ \\
Knees & $67(32.2 \%)$ & $21(31.3 \%)$ \\
Ankles/Feet & $82(39.4 \%)$ & $41(50 \%)$ \\
\hline
\end{tabular}

was $\chi^{2}(1, n=208)=5.330, p=0.021$, phi $\left.=0.172.\right)$, office chair support (Chi-square test for independence (with Yates Continuity Correction) showed a statistical significant association with a value of $\chi^{2}(1, n=208)=9.306, p=0.002$, phi $\left.=0.224\right)$, job worries had significance with a value of $\chi^{2}(1$, $n=208)=15.956, p=0.003$, current health status with a value of $\chi 2(1, n=208)=12.326, p=0.006$ and mental stress with a value of $\chi 2(1, n=208)=11.574, p=0.021$. All these associations are as they appear in Table 5. Despite not being statistically significant, there was increased likelihood of neck pain $(56.5 \%)$ and LBP $(63 \%)$ in those who worked for more than two hours at a time on the computer, neck pain $(39.2 \%)$ and LBP (42.9\%) for participants who spent more than one hour doing domestic activities and neck pain $(25.6 \%)$ and LBP $(27 \%)$ in those who spent less than one hour in hobbies and physical activities. Those who were overweight had increased likelihood of having LBP $(30.8 \%)$ unlike for neck pain whose highest prevalence was in those who had normal weight (29.6\%).

After administration of the knowledge-based ergonomic intervention, follow-up focus group discussions (FGDs) held to explore and describe the concepts that the participants valued from the ergonomics programme revealed that most participants valued
Table 5

Risk factors associated with LBP

\begin{tabular}{lcccc}
\hline Risk factors & Frequency & \multicolumn{2}{c}{ LBP } & Significance \\
\cline { 3 - 4 } & $n(\%)$ & Yes $(\%)$ & No $(\%)$ & $\begin{array}{c}\text { level } \\
(p<0.05)\end{array}$ \\
\hline Gender & & & & $\mathbf{0 . 0 2 1}$ \\
Male & & & & \\
Female & $86(41.5)$ & $58(28)$ & $29(14)$ & \\
Office chair support & $121(58.5)$ & $98(47.3)$ & $22(10.6)$ & \\
Yes & $103(50.2)$ & $68(43.9)$ & $35(70)$ & \\
No & $102(49.8)$ & $87(56.1)$ & $15(30)$ & \\
Job Worries & & & & $\mathbf{0 . 0 0 3}$ \\
Never & $25(12.1)$ & $14(6.8)$ & $11(5.5)$ & \\
Very occasionally & $33(16.0)$ & $29(14.1)$ & $4(1.9)$ & \\
Sometimes & $114(55.3)$ & $80(38.8)$ & $34(16.5)$ & \\
Often & $30(14.6)$ & $28(13.6)$ & $2(1.0)$ & \\
Always & $4(1.9)$ & $4(1.9)$ & $0(0)$ & \\
Current health status & & & & $\mathbf{0 . 0 0 6}$ \\
Very poor & $0(0)$ & $0(0)$ & $0(0)$ & \\
Poor & $2(1.0)$ & $1(0.5)$ & $1(0.5)$ & \\
Average & $49(23.7)$ & $42(20.3)$ & $7(3.4)$ & \\
Good & $124(59.9)$ & $96(46.4)$ & $28(13.5)$ & \\
Very good & $32(15.5)$ & $17(8.2)$ & $15(7.2)$ & \\
Mental stress level & & & & $\mathbf{0 . 0 2 1}$ \\
None & $20(9.7)$ & $10(4.9)$ & $10(4.9)$ & \\
Little & $88(42.7)$ & $63(30.6)$ & $25(12.1)$ & \\
Some & $63(30.6)$ & $53(25.7)$ & $10(4.9)$ & \\
Fairly much & $27(13.1)$ & $23(11.2)$ & $4(1.9)$ & \\
Very much & $8(3.9)$ & $6(2.9)$ & $2(1.0)$ & \\
\hline
\end{tabular}

The Pearson's chi-square test for independence showed a significant level of $p<0.05$ (with Yates Continuity Correction). Due to missing values the population frequency for the above variables are as follows: Gender $(n=207)$, Office chair support $(n=205)$, Job worries $(n=206)$, Current health status $(n=207)$ and Mental stress level $(n=206)$.

the information given. The FGDs consisted of eight participants with five $(62.5 \%)$ being female and three $(37.5 \%)$ male with a mean age of 37.5 years and mean number of years worked at 13 years. The prevalence of neck pain and LBP among these members was 50\% and $75 \%$ respectively and further discussions with the participants were best categorized into four themes outlined below. 


\subsection{Experiences of the participants with regards to the knowledge-based ergonomic programme}

Some participants were not new to ergonomic information; however they stated that the mode of live intervention was better appreciated and retained than getting information in form of e-mail communications: “... although we've received information related to ergonomic before, previously, I think from $H R$ and Occupational health coordinator, we've always had that information sent in the form of a mail and at times staff will not have time to read the mail or all emails..." (G1-P6). In addition, the intervention served as a reminder to those who knew about ergonomics "... I always remember and you know maybe to you, you thought you are doing your study, but am telling you, you've educated many..." (G2-P2) while to others it was an eye opener that helped them understand their body functions better "... so I just came to realize that there is a lot that most of us could prevent by just doing some simple exercises and, ummm, not keeping some positions which would really compromise our health..." (G1-P4).

\subsection{Knowledge of participants with regard to ergonomic-related low back and neck pain}

Participants' behaviour and attitude with regards to their lifestyle changes after the intervention was driven by their underlying knowledge. Some of the participants owned up to having had good behavioural practice even before the intervention "Actually, after sitting for a while you'll always find me in the corridors and my boss wonders 'what are you always doing on the corridors?' because I always take the breaks. That has been happening even before your talk" (G1-P3), but that it always took hard work to remind oneself about this “... I think the practicality of doing it or reminding yourself that I need to do, that is the issue"(G1-P1).

However some participants expressed to never having been conscious about how they behaved: "It's true; you know most often a lot, you know, when we sit, it's not at times you don't engage your minds when you are sitting. You just come, there's a seat, and you sit..." (G1-P1) "... because for me I never used to care how I sit." (G2-P2) other participants were thankful for the enlightenment that the intervention brought to their peer workers " ... but I have to take those breaks and at least am glad now that there were those exercises, OK you... somebody may pass there and wonder what is she doing, she must be crazy, but that's OK (people chuckling), it makes me relieve my pain." (G1-P3) and they further stated that the intervention enhanced their working relationships as supervisors could also understand the essence of taking exercise breaks from work.

\subsection{Challenges faced by participants in implementing ergonomic factors}

The participants indicated that they had challenges in different aspects with regards to behavioural changes which ranged from individual challenges, physical to environmental challenges. This, as one participant stated, was the fact that they had to change their routine behaviour: "It's not very interesting, I was used to a very comfortable posture of lying and sitting and watching anything I want on the Television. But now ... am forced to really try and discipline myself, but it's not that easy. Yes." (G1-P4). Participants said that environmental challenges like their workload and even the type of weather influenced their willingness to engage in extra physical activities. One often felt tired and needed to find time to rest.

Lack of compatibility between the office furniture was also posed as another challenge to compliance to good sitting posture. Participant G2-P1 had this to say: "I'd say the seats, there are some seats, whenever you sit, you'll feel like my back is either aching after some time." Participants, however, drew from the knowledge gained from the intervention and personal experiences and further encouraged each other to understand the importance of the exercises and good posture.

\subsection{Recommendations made towards the ergonomic intervention}

The participants further recommended that this program should be continued to enhance awareness in the wider society, decrease the cost of treating work-related disorders, help in decreasing negative behaviour associated with cultural myths as well as ensuring policy implementation with regard to prevention of WRMDs through the occupational health and safety teams in work places. One of the participant's expressed that:

"I was actually shocked by the figures... that she gave, she was doing a presentation that ... uhh... over $70 \%$ people are suffering with this kind of ailments and that was just a quick snapshot of what she did here and she quoted some figures of $90 \%$ of some other scholars who had done the same elsewhere. Now I saw this, eehh... as just an indication of the problems that we have not only in the institution here, but 
captured at large and, aahh... at some point in time I was even mentioning that this are some of these things to be stretched even further than just only the research area, because we don't see the country taking anything in terms of, eehh... like we have cancer days and all these things. We are not hearing any serious campaigns from the government, yet most of the population that we have in settings are all in offices most of them and you can be sure that this kind of problems is common and affects them." (G1-P4).

Equally, a participant who was privileged to be in the same group with one belonging to the health and safety committee challenged the member by finding out how they actually do help employees.

G2-P2: "Question? You are in that committee, Health and Safety Committee?"

G2-P1: "Mmhhh..."

G2-P2: "Do you, like, train people; do you give pamphlets or something? How do you help guys?"

G2-P1: "Very good question! (some chuckles) ... that committee was put up last year, late last year. So just hold your horses everything is in progress. We'll create an awareness soon..."

G2-P2: "You can actually be teaching us on that and just giving us information."

\section{Discussion}

The 12 month prevalence of LBP and neck pain in the study population was $75.5 \%$ and $68.7 \%$ respectively. This is higher than the prevalence in developed countries which ranges from $54 \%$ and $43 \%$ respectively for LBP and neck pain [54], a mean 1 year LBP prevalence of $37.8 \%$ in Greek public office workers [55], and neck pain prevalence of $45.5 \%$ among Belgian office workers. The comparison of prevalence of LBP and NP is seen to be more in the developing countries than in the developed countries. This discrepancy can be as a result of the difference in settings, or inferred to mean that in a span of almost ten years, the developed countries have somehow succesfully managed to decrease their prevalence rates.

Studies show that neck pain has been significantly associated with job worries and mental stress which was not the case in this study $[6,56,57]$. In this study, LBP was significantly associated $(p<0.05)$ with gender $(p=0.021)$, presence of full back support with office chair $(p=0.002)$, job worries $(p=0.003)$, mental stress $(p=0.021)$ and current health status $(p=0.006)$. Methodological differences could have led to the dis- crepancies seen between the findings of this study and what other studies found. The cross-sectional nature of this study was therefore a limitation in establishing causal relationships and hence future studies should consider longitudinal designs.

As noted in this study, the participants portrayed good knowledge of factors relating to both LBP and neck pain occurrences. However, this knowledge was not directly translated into behaviour that prevented the occurrence of work related LBP and neck pain. With regards to occupational safety, a study on workers in a Nigerian refinery showed that $44 \%$ of the workers suffered from work-related injuries inclusive of LBP [58]. However, there was still no complete compliance to the required safety measures at work, despite the fact that these workers were knowledgeable of the occupational hazards they were exposed to. Human behaviour is thus complex and there is a need for further studies, to find the most effective health promotion behavioural model that would help decrease both the incidence and prevalence of WRMDs [59, 60]. Sveson et al. [61] add that human beliefs and behaviour change over time; therefore, it is important to continually give education so as to increase the participants' confidence in the skills gained and, thereafter, evaluate their effects in order to detect the dominant factors that led to adherence or lack of adherence of proper health related behaviours. Failure to analyse the knowledge section before the intervention served as a limitation as the researcher could have emphasized more on behavioural change based on facts from the study's findings. Further research should thus be administered in the form of longitudinal studies in order to bring out the true picture of compliance to the relevant variables, considering the multifactorial aetiology of the WRMDs. Compliance as confirmed by WHO and ILO would thus enhance productivity in the work place as well as the general well-being of workers [62].

The knowledge-based ergonomic intervention was meant to influence participants' behaviour with regard to their work habits $[32,33,36]$. Participants expressed that the majority of people were not knowledgeable on the impact of ergonomic hazards on their daily lives and persisted in unsafe behavioural practice, giving rise to increased prevalence of WRMDs. They reiterated that awareness should be created, and not only to include office workers, but rather the general population at large. They noted the inequity in dissipation of knowledge of public health concerns by the health fraternity, and further stated that physiotherapists should be seen as proactive in ensuring mass information, that could even help people question cultural beliefs, that 
influence poor health behaviour. Equipping workers with knowledge of ergonomic hazards and selfprotection was therefore seen as their fundamental human right, that will act as an investment for economic productivity of a healthy workforce as well as saving costs to treat WRMDs [26, 63]. General public awareness, e.g. in the form of mass media, as recommended by several authors, as well as the findings of this study from the FGDs, would therefore act as a cue to action in seeing improved compliance with work safety regulations [26, 64, 65 (unpublished data), 66].

Despite the knowledge gained from the ergonomic intervention, literature shows that there needs to be a complementary action from work institutions to modify the work stations that would see effective results $[32,63]$. The health belief model (HBM) regards behavioural change to be dependent on one's knowledge of the subject matter, as well as perceived costs in comparison to the benefits of the problem [66, 67]. Further studies add that healthy behavioural change was easier for those who regarded the financial cost of adjustments as affordable [64, 66, 68, 69]. As shown in this study, participants appreciated the role that the ergonomics intervention played in making supervisors and top management understand the importance of work rest breaks as one of the preventative actions taken for WRMDs. All stakeholders are thus needed to take action in order to make lasting changes that will prevent the rampant effect of WRMDs amongst administrators [17, 62, 69-72].

With regard to policy enforcement, despite the fact that some studies done in Kenya have shown an improvement in compliance to Occupational Health and Safety (OHS) regulations from 35\% to $64.49 \%$ $[64,73]$, the participants from the FGDs constantly reiterated the need for the Occupational Health and Safety Board to be proactive in ensuring workers' safety in the workplace. They further stated that the presence of this Board as well as joint measures by other relevant stakeholders, e.g. the Kenya Bureau of Standards (KBS) and physiotherapists, will ensure the certification of the appropriate furniture that is produced for institutional use. The Occupational Health and Safety Board in each institution was a requirement by the International Labour Organization (ILO) to govern the safety of workers and hence the government should help in tightening and ensuring the implementation of such measures [26, 64, 74]. In addition to policy implementation, the curricula for the health professionals should therefore orient them towards disease prevention as a form of management with incorporation of the psychosocial factors involved [66, 73, 75]. These authors, as well as Ranasinghe et al. [63], further add that the spread of already known knowledge and continuous evaluation by the health practitioners and policy makers would help increase the personal responsibility taken by workers towards their own health, thereby ensuring cost-effectiveness in preventive management of WRMDs.

\section{Conclusion}

Musculoskeletal disorders are fast becoming a burden of disease all around the world and more so in relation to LBP and neck pain. There has been an identified gap of literature with regard to physiotherapy services and occupational illnesses, and the findings of this study sought to address this gap. There is a high prevalence of LBP and neck pain in the study area, which necessitates continual ergonomic education to translate participants' knowledge into compliance of behaviour that will reduce ergonomic related LBP and neck pain. From the outcome of this study, some recommendations are made to various institutions to help increase the general well-being of individuals with regards to their health; increase the country's economy as a result of increased work productivity; reduce the burden on health care professionals in treating and managing cases that would have been prevented, as well as reduce the medical expenditure incurred in treating WRMDs.

- Employers should have an occupational health and safety board in each institution that incorporates the relevant disciplines in giving of continuous ergonomic education; assesses, evaluates and monitors work station adjustments as well as organisational factors that could lead to development of WRMDs.

- Through reinforcement by the government (Ministries of Health and Labour) and the different stakeholders, e.g. physiotherapists, there should be creation of a database to record work-related injuries and promotion of research as well as continuous audits of the same so as to monitor and evaluate the incidence and prevalence of WRMDs.

- The government should be at the forefront in intersectoral collaboration through the Ministries of Health and Labour to reinforce the implementation of the health and safety requirements. This collaboration will go a long way in ensuring that 
the Occupational Health and Safety act is not only theorized, but also actually put to practice, and offenders against this Act should be convicted.

- The training of professionals in Occupational health and safety must be facilitated to reinforce the understaffed workers in carrying out audits at work places. Occupational health and safety should also be introduced as part of the curriculum in schools to act as a primary prevention of WRMDs. This, coupled with health education in the form of mass media, should also be implemented among the general public to help create awareness and the prevention of WRMDs.

\section{Acknowledgments}

I wish to express my heartfelt gratitude to the AKUH, $\mathrm{N}$ and the participants of this study for the support they accorded me.

\section{References}

[1] Hoy D, Bain C, Williams G, March L, Brooks P, Blyth F, et al. A systematic review of the global prevalence of low back pain. Arthritis and Rheumatism 2012;64(6):2028-37.

[2] Krismer M, Van Tulder M. Low back pain (non-specific). Best Practice and Research Clinical Rheumatology 2007;21(2): 77-91.

[3] Hoy D, Brooks P, Blyth F, Buchbinder R. Epidemiology of low back pain. Best Practice \& Research Clinical Rheumatology 2010;24: 769-81.

[4] Cagnie B, Danneels L, Van Tiggelen D, De Loose V, Cambier D. Individual and work related risk factors for neck pain among office workers: A cross sectional study. European Spine Journal 2007;16:679-86.

[5] Collins R, Janse Van Rensburg D, Patricios J. Common work-related musculoskeletal strains and injuries. South African Family Practice: Official Journal of the South African Academy of Family Practice/Family Care 2011;53(3):240-6.

[6] Côté P, van der Velde G, Cassidy DJ, Carroll JL, Hogg-Johnson $\mathrm{S}$, Holm WL, et al. The burden and determinants of neck pain in workers. European Spine Journal 2008a;17(Suppl 1):S60-74.

[7] Ferrari R, Russell A. Neck Pain. Best Practice \& Research Clinical Rheumatology 2003;17(1):57-70.

[8] Chetty L. Musculoskeletal injury patterns at an occupational health physiotherapy clinic in The United Kingdom. The Internet Journal of Rheumatology 2010b;6(2):ISSN:1528-8412.

[9] Fisher T, Gibson T. A measure of University Employee's Exposure to Risk factors for work-related musculoskeletal disorders. American Association of Occupational Health Nurses 2008;56(3): 107-14.

[10] Naidoo NR, Haq AS. Occupational Use Syndromes. Best Practice \& Research Clinical Rheumatology 2008;22(4):677-91.

[11] Silverstein B, Adams D. Work-related Musculoskeletal Disorders of the Neck, Back, and Upper Extremity in Washington State, 1997-2005: Technical Report Number 40-11-2007
December 2007. Retrieved August 20, 2012, from Safety and Health Assessment and Research for Prevention (SHARP) Washington State Department of Labor and Industries.: http://www.Ini.wa.gov/Safety/Research/Files/2007Wmsd Rpt.pdf.

[12] Widanarko B, Legg S, Stevenson M, Devereux J, Eng A, 't Mannetje A, et al. Prevalence and work-related risk factors for reduced activities and absenteeism due to low back symptoms. Applied Ergonomics 2012;43:727-37.

[13] Chetty L. Physiotherapy and ergonomics for a work-related musculoskeletal disorder. International Journal of Therapy and Rehabilitation 2010a;17(2):83-91.

[14] Cram JR, Durie M. The History of Muscle Dysfunction and SEMG. In Cram JR, Criswell E, Cram's Introduction to Surface Electromyography 2010;175-188. Google Books: Biofeedbackinternational.com/semg4.htm: Jones \& Bartlett Learning.

[15] Corlett E. Ergonomics and sitting at work. Work 2009;34: 235-8.

[16] Janwantanakul P, Pensri P, Jiamjarasrangsri V, Sinsongsook T. Prevalence of self-reported musculoskeletal symptoms among office workers. Occupational Medicine 2008;58: 436-8.

[17] David G, Woods V, Li G, Buckle P. The development of the Quick Exposure Check (QEC) for assessing exposure to risk factors for Work-related musculoskeletal disorders. Applied Ergonomics 2008;39(1):57-69.

[18] Niu S. Ergonomics and Occupational Safety and health: An ILO perspective. Applied Ergonomics 2010;41(6):744-53.

[19] Punnet L, Wegman DH. Work-related musculoskeletal disorders: The epidemiological evidence and the debate. Journal of Electromyography and Kinesiology 2004;14:13-3.

[20] ILO. Global Strategy on Occupational Safety and HealthConclusions Adopted by the International Labour Conference at its 91st session 2003 Retrieved 03 14, 2011, from ILO: http://www.ilo.org/wcmsp5/groups/public/@ed_protect.

[21] Zhang B, Alvarez-Casado E, Occhipinti E, Mondelo P. Toolkits for hazard identification, risk assessment and prevention of work-related musculoskeletal disorders based on a collaborative platform. International Conference on Occupational Risk Prevention "8th International Conference on Occupational Risk Prevention. 2010 Valencia: http://upcommons.upc.edu/eprints/bitstream/2117/8402/1/1447_TIAM.pdf.

[22] Health and Safety Executive. (2010/2011). Annual Statistics Report. www.hse.gov.uk/statistics/.

[23] Rosenstock L, Cullen M, Fingerhut M. Occupational Health. In Disease Control Priorities in Developing Countries 2006;1127-46.

[24] Nyakango, J. Summary status of Occupational Health and Saftey in Kenya. 2005 Retrieved 03 15, 2011, from Workshop on the IUPAC-UNESCO-UNIDO Safety Training Program, part of the IUPAC Congress in Beijing, on Wednesday, August 17: http:old.iupac.org/standing/coci/STP.../05/-Nyakango.pdf

[25] Kenya Profile. (2004-2005). Retrieved 04 04, 2012, from Country Profile: Kenya: http://www.mongabay.com/ reference/country_profiles/2004-2005/Kenya.html

[26] Muigua, K. Realising Occupational Safety and Health as a Fundamental Human Right in Kenya. 2011, Retrieved August 14, 2012, from Kariuki Muigua and Company Advocates: http://www.kmco.co.ke/index.php/publications/realisingoccupational-safety-and-health-as-a-fundamental-humanright-in-kenya.

[27] Kenya DO. Kenya, Directorate Occupational Safety and Health Services: Report of CIS Activities for The 2009/ 10. 2009/10 Retrieved 039 2011, from Ministry of Labour 
Act: www.ilo.org/wcmsp5/groups/public/—ed.../wcms_144 190.pdf

[28] Mwanthi PM. African newsletter on occupational health and safety. Planning of Ergonomics Research at Work Place 2009;19:40-1.

[29] Muchiri F. Occupational Safety and Health Bill. 2003, Retrieved 03 8, 2011, from Occupational Health and Society.

[30] Ramazzini B. Voices From the Past: De Morbis Artificum Diatriba [Diseases of Workers]. American Journal of Public Health 2001;91(9):1380-2.

[31] Dockrella S, Earleb D, Galvina R. Computer-related posture and discomfort in primary school children: The effects of a school-based ergonomic intervention. Computers \& Education 2010;55(1): 276-84.

[32] Ismail SA, Tamrin SB, Baharudin MR, Noor MA, Juni MH, Jalaludin $\mathrm{J}$, et al. Evaluation of two ergonomics intervention programs in reducing ergonomic risk factors of musculoskeletal disorder among school children. Research Journal of Medical Sciences 2010;4(1): 1-10.

[33] Robertson M, Amick BC, De Rango K, Rooney T, Bazani L, Harrist R, et al. The effects of an office ergonomics training and chair intervention on worker knowledge, behaviour and musculoskeletal risk. Applied Ergonomics 2009;40(1):124-35.

[34] Wedderkopp N, Kjaer P, Hestbaek L, Korsholm L, LeboeufYde C. High-level physical activity in childhood seems to protect against low back pain in early adolescence. The Spine Journal 2009;9:134-41

[35] Woolf AD, Brooks P, Akesson K, Mody GM. Prevention of musculoskeletal conditions in the developing world. Best Practice \& Research Clinical Rheumatology 2008;2(4): 759-72.

[36] Amick CB, Robertson MM, DeRango K, Bazzani L, Moore A, Rooney $\mathrm{T}$, et al. Effect of office ergonomics intervention on reducing musculoskeletal symptoms. Spine 2003 ; 28(24):2706-11

[37] Leech NL, Onwuegbuzie AJ. A typology of mixed methods research designs. Springer Science Quality and Quantity 2009;43(2):265-75

[38] Israel DG. Sampling The Evidence Of Extension Program Impact. In Determining Sample size. Florida: Institute of Food and Agricultural Sciences (IFAS) 1992.

[39] De Barros EN, Alexandre NM. Cross-cultural adaptation of the Nordic musculoskeletal Questionnaire. International Council of Nurses, International Nursing Review 2003;50:101-8.

[40] Maciel SC, Jennings F, Jones A, Natour J. The development and validation of a low back pain knowledge questionnaireLKQ. Clinics 2009;64(12):1167-75.

[41] Niyobuhungiro P. The Effects of Back Eduation Programme Among employees at an Industrial Setting in Cape Town,South Africa. Unpublished Masters Thesis 2008;35-37.

[42] Korhonen T, Ketola R, Toivonen R, Luukkonen R, Hakkanen M, Viikari-Juntura E. Work related and individual predictors for incident neck pain among office employees working with video display units. Occupational and Environmental Medicine 2003;60:475-82.

[43] Evans O, Patterson K. Predictors of neck and shoulderpain in non-secretarial computer users. International Journal of Industrial Ergonomics 2000;26:357-65.

[44] nd. Ergonomics Exercises. 2012 Retrieved December 30, 2011, from Ergonomics-Info.com: http://www.ergonomicsinfo.com/ergonomic-exercises.html.

[45] Driessen TM, Proper IK, Anema RJ, Bongers MP, Van der Beek JA. Process evaluation of a Participatory ergonomics Programme to prevent Low bak pain and neck pain among workers. Implementation Science 2010;5(65): doi:10.1186/1748-5908-5-65

[46] Da Costa BR, Vieira ER. Stretching to reduce work-related musculoskeletal disorders: A systematic review. Journal of Rehabilitation Medicine 2008;321-8.

[47] Nelson GA, Kokkonen J. Stretching Anatomy. USA: Human Kinetics 2007.

[48] Kilbolm A. Editorial Prevention of work-related musculoskeletal disorders in the worplace. International Journal of Industrial Ergonomics 1998;21:1-3.

[49] Lühmann D, Stoll S, Burkhardt-Hammer T, Raspe H. Prevention of relapsing back ache. German Medical Science Health Technology Assessement 2006;2:12.

[50] n.d. 2012, Human Resources, General Exercises- Get active at work. Retrieved December 29, 2011, from Western University: http://www.uwo.ca/hr/safety/ergo_rehab/general.html.

[51] n.d. Ankle Exercises. Retrieved January 17, 2012, from Shape Fit.com: http://www.shapefit.com/ankle-exercises.html.

[52] Hedenschoug K. Back and Neck Exercises Pamphlet. Retrieved January 13, 2011, from University of Missouri, 2006, Columbia - Department of Physical Therapy: medicine. missouri.edu/ortho/spine/docs/NeckBackExercises.pdf.

[53] Creswell JW. Research design : Qualitative, Quantitative, and Mixed Methods Approaches (2nd ed.). California: Thousands Oaks, Sage Publications 2003.

[54] Widanarko B, Legg S, Stevenson M, Devereux J, Eng A, t' Mannetje AC, et al. Prevalence of musculoskeletal symptoms in relation to gender, age, and occupational/industrial group. International Journal of Industrial Ergonomics 2011;41:56172.

[55] Spyropoulos P, Papathanasiou G, Georgoudis G, Chronopoulos E, Koutis H, Koumoutsou F. Prevalence of low back pain in Greek public office workers. Pain Physician 2007;10:651-60.

[56] Green BN. A literature review of neck pain associated with computer use: Public health implications. Journal of the Canadian Chiropractic Association 2008;52(3):161-8.

[57] Panwalkar S. Work-related neck pain amongst university administrative staff. Unpublished master's thesis, University of the Western Cape, Bellville, Cape Town, South Africa 2008.

[58] Aliyu AA, Saidu S. Pattern of occupational hazards and provisions of occupational health services and safety among workers in kaduna refinery and petrochemical company limited (KRPC), Kaduna, Nigeria. Continental Journal of Tropical Medicine 2011;5(1):1-5.

[59] Côté P, Kristman V, Vidmar M, Van Eerd D, Hogg-Johnson $\mathrm{S}$, Beaton $\mathrm{D}$, et al. The prevalence and incidence of work absenteeism involving neck pain. European Spine Journal 2008b;17(Suppl 1):S192-8.

[60] Jiang Y, Ong MK, Tong EK, Yang Y, Nan Y, Gan Q, et al. Chinese physicians and their smoking knowledge, attitudes, and practices. American Journal of Preventive Medicine 2007;33(1):15-22.

[61] Sveson LW, Carmel S, Varnhagen CK. A review of the knowledge, attitudes and behaviours of university students concerning HIV/AIDS. Health Promotion International 1997;12(1):61-8.

[62] Eijkemans G. WHO and ILO joint effort on occupational health and safety in Africa. Africa Newsletter on Occupational Health and Safety 2004;14:28-9.

[63] Ranasinghe P, Perera YS, Lamabadusuriya DA, Kulatunga S, Jayawardana N, Rajapakse S, et al. Work related complaints of neck, shoulder and arm among computer office workers: 
A cross-sectional evaluation of prevalence and risk factors in a developing country. Environmental Health 2011;10:70.

[64] Nzuve SN, Lawrence BA. The extent of compliance with occupational safety and health regulations at registered work places in Nairobi. International Journal of Business, Humanities and Technology 2012;2(2):1-6.

[65] Ng'uurah JN, Frantz J. Health education needs among individuals with low back pain. Unpublished Masters Thesis, The University of the Western Cape, Bellville, Cape Town, South Africa 2004.

[66] Becker MH, Haefner DP, Kasl SV, Kirscht JP, Malman LA, Rosenstock IM. Selected psychosocial models and correlates of individual health-related behaviours. Medical Care 1977;15(5): 27-46.

[67] Glanz K. Theory at a Glance: A Guide for Health Promotion Practice. 2005 Retrieved September 9, 2012, from http://www.cancer.gov/cancerinformation/theory-at-a-glance.

[68] Woodcock A. Ergonomics, education and children: A personal view. Ergonomics Volume 2007;50(10):1547-60.

[69] Driessen M, Proper K, Anema J, Knol D, Bongers P, van der Beek A J. The effectiveness of participatory ergonomics to prevent low-back and neckpain- results of a cluster randomized controlled trial. Scandinavian Journal of Work and Environmental Health 2011;37(5):383-93.
[70] Bongers PM, Ijmker S, van den Heuvel S, Blatter BM. Epidemiology of work related neck and upperlimb problemss: Psychosocial and personal risk factors (Part I) and effective interventions from a bio behavioural perspective (Part II). Journal of Occupational Rehabilitation 2006;16:279-302.

[71] Romer D, Hornick R. HIV education for youth: The importance of social consensus in behaviour change. AIDS Care: Psychological and Socio-Medical Aspects of AIDS/HIV 1992;4(3):285-303.

[72] Makhonge PW. African newsletter on occupational health and safety. Planning of Occupational Safety and Health Activities 2009;27.

[73] Mbakaya CF, Onyoyo HA, Lwaki SA, Omondi OJ. A survey on management perspectives of the state of workplace health and safety practices in Kenya. Accident Analysis and Prevention 1999:31:305-12.

[74] Afubwa SO. Public health officer in occupational health and safety in Kenya. African Newsletter on Occupational Health and Safety 2004;14:10-2.

[75] Rantanen J, Lehtinen S, Savolainen, Kai. The opportunities and obstacles to collaboration between the developing and developed countries in the field of occupational health. Toxicology 2004; 198:63-74. 